\title{
Mental-Attentional Capacity: Does Cognitive Style Make a Difference?
}

\author{
Raymond Baillargeon \\ Université de Montréal, Montréal, Québec, Canada \\ E-mail: baillarr@ere.umontreal.ca \\ and \\ Juan Pascual-Leone and Caroline Roncadin \\ York University, North York, Ontario, Canada \\ E-mail: juanpl@yorku.ca
}

\begin{abstract}
There is currently no consensus on whether the difference between field-dependent and fieldindependent subjects on tasks of cognitive abilities result from different mental processing strategies, from true group differences in cognitive ability, or from both. School-age children $(N=239)$ were tested for field dependence/independence using the Children's Embedded Figures Test and for mental-attentional capacity using the Figural Intersection Task. Multigroup scaling models were used to separate the contributions of style from ability in children's performance on Figural Intersection items. Results show that field-dependent children have greater odds of success than field-independent children in Figural Intersection items when the task's mental-attentional demand is above the child's mental attentional capacity, as assessed in the same task. The contrary is true when the task's mental-attentional demand is below or equal to the mental-attentional capacity of the child. Overall, field-dependent children obtain lower estimates of mental-attentional capacity than field-independent children in this task. We discuss the implications of these results for the measurement of mental-attentional capacity and the conceptualization of field dependence/ independence. (๑) 1998 Academic Press
\end{abstract}

Preparation of this paper has been supported by a research grant from the Social Sciences and Humanities Research Council of Canada to the second author and by a postdoctoral fellowship from the Fonds de Recherche et de Formation des Chercheurs to the first author. We are indebted to James O. Ramsay, Frank Vitaro, Janice Johnson, Serge Larivée, H. Wayne Reese, Claude L. Normand and Sandra Cunning for thoughtful comments and constructive criticisms.

Address correspondence and reprint requests to either Juan Pascual-Leone, Department of Psychology, York University, 4700 Keele Street, North York, Ontario, Canada M3J 1P3, or Raymond Baillargeon, Centre de Recherche Fernand-Seguin, 7331, rue Hochelaga, Montréal, Québec, Canada H1N 3V2.) 
A basic distinction exists between cognitive abilities and cognitive styles. Cognitive abilities refer to the necessary know-how, content, or complexity level of cognition, whereas cognitive styles refer to a chosen, optional manner or form of cognition (Globerson \& Zelniker, 1989; Messick, 1987). Often cognitive styles differ from cognitive abilities in terms of the abstract continuum underlying each dimension of individual differences. Abilities are basically unipolar and value directional (Messick, 1987, 1993b)-ranging from very little at one extreme to a great deal at the other. In contrast, cognitive styles are typically bipolar and value differentiated (Messick, 1987, 1993b; Witkin \& Goodenough, 1981), with each pole having adaptive features under different circumstances. Because cognitive style may play a role not only in the expression but also in the development of cognitive ability, it has proven difficult to separate the relative contribution of style from ability in tests aimed at assessing the child's cognitive capacity (Messick, 1993a). The present study represents such an attempt.

One cognitive style where the issue of directional value versus differentiated value is particularly controversial is field dependence/independence (Globerson \& Zelniker, 1989; Messick, 1984; Pascual-Leone, 1989; Witkin, Dyk, Faterson, Goodenough, \& Karp, 1962; Witkin \& Goodenough, 1981). This cognitive style was originally inferred from consistent individual differences on tests of individuals' success in perceiving gravitational upright position under conditions in which there is a conflict between visual and vestibular cues (Pascual-Leone, 1969, 1989; Witkin, Lewis, Hertzman, Machover, Meissner, \& Wapner, 1954). In the Rod-and-Frame Test, for example, the conflict was tacitly created by asking a subject to adjust to the true vertical a luminous rod surrounded by a luminous tilted frame in an otherwise dark room. Individuals who relied more heavily on visual cues than on bodily (gravitational or vestibular) cues in resolving the conflict did poorly on the Rod-and-Frame Test and were labeled field dependent; individuals who relied more on bodily cues did well on the Rod-and-Frame Test, and were labeled field independent.

What is the interplay between cognitive development and cognitive style? Many studies have reported that field-independent people do better than fielddependent people on a variety of tasks designed to measure cognitive ability (e.g., Globerson, 1983,1985, 1989; Pascual-Leone, 1969; Witkin, Dyk, Faterson, Goodenough, \& Karp, 1962; Witkin \& Goodenough, 1981), but this difference remains controversial with regard to its causal determinants. For instance, adopting a dialectical constructivist model such as the one proposed by Pascual-Leone (Pascual-Leone, 1969, 1970, 1987, 1989, 1995; Pascual-Leone \& Goodman, 1979) we might ask: Do field-dependent subjects mobilize and/or allocate their mental-attentional resources less efficiently than field-independent people of the same mental-attentional capacity or do they have a smaller mental-attentional capacity? Mental-attentional capacity (Pascual-Leone, 1987; Pascual-Leone \& 
Baillargeon, 1994) is the endogenous attentional resource (often loosely called "working memory") which enables subjects to keep in mind, via endogenous activation of corresponding schemes (i.e., information-carrying functional unit processes), a given number of task features or constraints that are not directly activated by the perceptual situation.

According to the first alternative, field-dependent people possess as much mental-attentional capacity as their same age field-independent peers, but they lack sophisticated executive schemes to mobilize and/or allocate mental-attentional capacity appropriately. From this perspective, field dependence/independence would be interpreted as a performance rather than a competence (i.e., capacity deficiency) variable (deRibaupierre \& Pascual-Leone, 1979; Globerson, 1989; Linn, 1978; Neimark, 1981, 1981,Messick, 1987, 1993b; Zelniker, 1989).

\section{MISLEADING SITUATIONS, INFORMATION-PROCESSING STRATEGIES, AND THE FIGURAL INTERSECTION TASK}

Complex relationships between cognitive abilities and cognitive styles can be understood via a model of the processes that generate performance in misleading situations (Pascual-Leone \& Baillargeon, 1994). Such an account, originally proposed by Pascual-Leone $(1969,1989)$, rests on the assumption that performance in misleading situations results from a complex formula of underlying organismic factors (i.e., situation-free organismic resources of the psychological organism). Misleading situations can be contrasted with facilitating situations in that they constitute two different modes of selective attention (Pascual-Leone, 1987, Pascual-Leone), 1995). Only in misleading situations does the context elicit schemes that are not relevant, or even compatible, with the task (PascualLeone, 1980, 1984, 1987, 1989).

A somewhat related distinction exists between automatic and controlled processes (Shiffrin, 1988), the latter entailing the use of mental effort (Hasher \& Zacks, 1979; Kahneman, 1973). Mental effort is explicated by Pascual-Leone (1984) as resulting from the enactment of either mental power or active attentional inhibition. Mental power is defined as the power of the subject's allocatable mental attentional capacity (i.e., the highest number of distinct schemes that it can bring to hyperactivation when allocated). Performance in misleading situations is thus a function of controlled processes. Tasks designed to measure field dependence/independence are usually misleading situations (Pascual-Leone, 1969, 1989, 1995). One such task is the Embedded Figures Test in which the respondent is asked to trace a simple geometric figure embedded within a complex drawing. The complex drawing acts as a "misleading/embedding context" which hides the simple figure. An effortful strategy involving controlled processes is then needed to extract the simple figure from the complex drawing.

Misleading situations like this one elicit a conflict between two qualitatively different mental strategies that compete to produce performance (Pascual-Leone, 1989; Pascual-Leone \& Baillargeon, 1994). There are the "contextually driven 
strategies" (hereafter referred to as Y-strategies), which create a misleading/ embedding context. In the Embedded Figures Test, the Y-strategies compel the subject to structure the complex drawing as an integrated/embedding whole, and thus prevents perception of the simple figure. In our theory (Pascual-Leone \& Baillargeon, 1994), Y-strategies are facilitated by associative content learning (Pascual-Leone's C learning), by automatization/overlearning of logical strategies, i.e., coordinated scheme patterns of activation and application (PascualLeone's LC learning) and by the Gestaltist field (F) factors, i.e., mechanisms generating Gestaltist and S-R compatibility effects. There are also the "executive-driven strategies" (hereafter referred to as X-strategies) which can overcome the misleading/embedding context created by Y-strategies. In the Embedded Figures Test, the $\mathrm{X}$-strategies lead to perception of the simple figure by mapping its distinctive features into corresponding features of the complex drawing, and thus breaking down the cohesiveness of the complex drawing that hides the simple figure (Pascual-Leone, 1969), 1989; Pascual-Leone \& Goodman, 1979). The intentional restructuring process taking place with the $\mathrm{X}$-strategies demands use of several mental-attentional resources (Pascual-Leone, 1987; Pascual-Leone \& Baillargeon, 1994). In implementing the X-strategies, subjects have to use sophisticated executive schemes to mobilize and allocate mental capacity and active attentional inhibition ("interrupt" capacity).

According to Pascual-Leone's model of field dependence/independence (Pascual-Leone, 1969, 1989; Pascual-Leone \& Morra, 1991) field-independent subjects are characterized by a disposition to use efficient $\mathrm{X}$-strategies but relatively inefficient Y-strategies. Conversely, field-dependent subjects are characterized by a disposition to use efficient $\mathrm{Y}$-strategies but relatively inefficient X-strategies.

A misleading situation specially designed to assess mental-attentional capacity (in a context that also demands active attentional inhibition) is the Figural Intersection Task (Pascual-Leone \& Ijaz, 1989) (Fig. 1). Every item of this task presents, on the right-hand side of the page, a number of individual geometric shapes (this is the "presentation set"). Shapes in the presentation set are the item's relevant figures. The number of these figures in each item varies randomly from 2 to 8 , and this number $\mathrm{j}$ defines the mental demand of the item. On the left-hand side there is a figural compound (this is the "compound set") with all relevant (i.e., right-hand side) figures overlapping in a common total intersection. In some items there is also one irrelevant figure, not found in the presentation set, which is not included in the total intersection. When present, the irrelevant figure is a distractor and must be ignored. In every item the child must first (a) place a dot inside each and every shape found on the right-hand side and then (b) place a single dot on the left-hand side that is inside all the relevant figures at the same time. Because the figural compound of the left-hand side is perceptually integrated (Gestaltist field factor) into a single complex drawing, the total intersection of relevant figures is not easy to see and must be found by locating the 

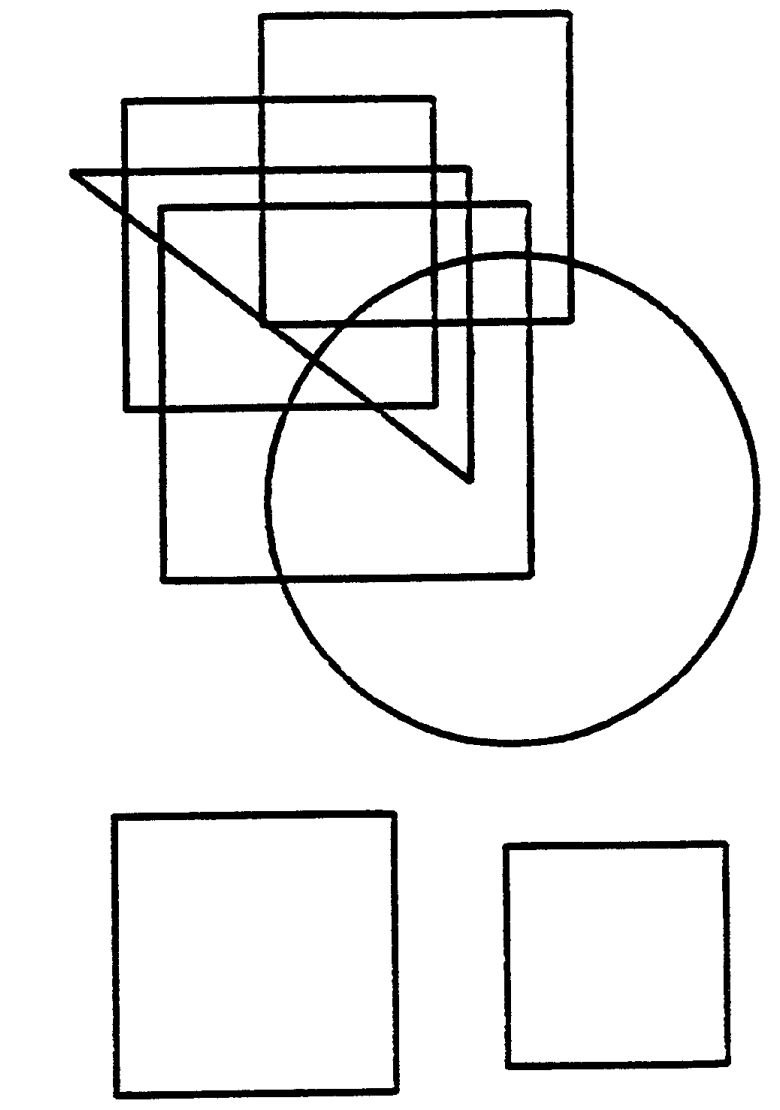

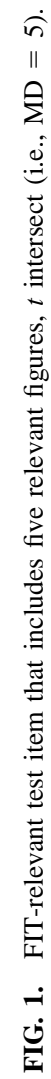


relevant figures one by one and then seeking the intersection. This perceptual activity requires the use of mental attentional capacity (see Pascual-Leone \& Baillargeon, 1994, for a more formal task analysis).

Performance on a task like the Figural Intersection Task depends on two different theoretical parameters. The first, mental power (Mp), refers to the maximum number of schemes that the individual can endogenously activate (or "boost") at the same time using mental attention. We believe that mental power increases in graded levels until the age of 16 years (Pascual-Leone, 1970, 1987). The second theoretical parameter, mental demand (Md), refers to the minimum number of schemes that one must keep in mind for the solution of a task or test item. Thus mental demand is the minimum amount of mental power that an individual must have in order to pass the task/item in question. Mental power and its derivative mental demand can be assessed empirically by combining task analysis (Pascual-Leone, 1997; Pascual-Leone \& Baillargeon, 1994; PascualLeone \& Johnson, 1991) with a suitable method of task construction (PascualLeone, 1980; Pascual-Leone, Baillargeon, Lee, \& Ho, 1991). In constructing the Figural Intersections Task, levels are obtained by varying the number of figures to be intersected. This method of graded levels is not used in tasks/tests of field dependence/independence (or other cognitive styles).

\section{COGNITIVE-STYLE PROCESS POSTULATES ON THE FIGURAL INTERSECTION TASK}

According to our theory, testing a child can lead to two very different outcomes depending upon the relationship between the mental power of the child and the mental demand of the task. If the item's mental demand is above the child's mental power the child should fail; if the item's mental demand is below or equal to the child's mental power the child should succeed. Because this relation varies among individual items within the same task, there is a pattern of pass/fail probabilities. We call this pattern a mental demand/mental power trade-off (Pascual-Leone \& Baillargeon, 1994). Note that this predicted pattern can fail in two different ways. First, there may be a false-positive error in which the child succeeds on a test item despite the fact that mental demand exceeds the child's mental power. Second, there may be a false-negative error in which the child fails despite the fact that mental demand is below or equal to the child's mental power. Pascual-Leone and Baillargeon (1994) suggest that these errors are caused by cognitive conflicts like those described above between $\mathrm{X}$ - and Y-strategies.

This is another postulate of our model: In situations where the test item's mental demand is above the child's mental power, Y-strategies should dominate the X-strategies. And thus whenever executive-driven $\mathrm{X}$-strategies cannot be implemented (due to a lack of mental-attentional capacity) the individual will use perception-driven Y-strategies to cope with the task. An example of a Y-strategy that could lead to a correct performance in the Figural Intersections Task is a 
figurative response bias caused by automatized strategies in combination with the Gestaltist field factor. One such Y-strategy could be a pattern of exploring, e.g., searching for the area of common intersection within a high-density region of the figural compound. Since such strategies often facilitate success in difficult items, false-positive errors will tend to occur with children who rely on automatized strategies. Other sources of false-positive errors are facilitated by similar factors. Pascual-Leone and Baillargeon (1994) discuss these strategies in detail. Both field-dependent and field-independent people face a cognitive conflict between X- and Y-strategies in the Figural Intersection Task (Pascual-Leone, 1969, 1989). The outcome of this conflict is predicted to be different for both groups, however, because the causal factors (content learning, structural overlearning, and the Gestaltist field factor) are theoretically much stronger in field-dependent than in field-independent individuals (Pascual-Leone, 1989; Pascual-Leone \& Morra, 1991). Consequently, in situations where the item's mental demand is above the child's mental power (i.e., Md > Mp), field-dependent children should have higher probability of success than field-independent children. This is the first hypothesis to be tested in our study.

A third postulate of our model is that whenever the item's mental demand is below or equal to the child's mental power (i.e., $\mathrm{Mp} \geq \mathrm{Md}$ ), $\mathrm{X}$-strategies should dominate Y-strategies. Thus, when a task is not too complex for the child's mental power, he/she should be able to overcome the misleading initial structure of the situation imposed by Y-strategies (e.g., the complex-drawing pattern of the item's left-hand side). To do so a child needs sophisticated executive schemes that mobilize and allocate mental-attentional resources to activate relevant schemes and inhibit irrelevant ones. False-negative errors (i.e., failure in items when $\mathrm{Mp} \geq \mathrm{Md}$ ) might occur when these executive-driven X-strategies are not well implemented. For example, Gestaltist field effects that hinder perceptual segregation of relevant figures within the figural compound might produce false-negative errors. But executive schemes allocating and mobilizing the mental energy and mental interrupt are theoretically much more efficient in fieldindependent than in field-dependent subjects. Thus, in situations where the test item's mental demand is below or equal to the child's mental power, fieldindependent children should have a higher probability of success than fielddependent children. This is the second hypothesis to be tested in this study.

\section{METHOD}

\section{Participants}

A total of 239 children were tested from two elementary schools in the York Region Separate School Board, a region bordering with metropolitan Toronto. One elementary school offered a program for gifted children. Of the 224 subjects for whom we obtained scores on both the dependent (i.e., mental-attentional capacity) and independent (i.e., field dependence/independence) variables, 124 were male and 100 were female. The distribution of children by sex, giftedness, 
TABLE 1

Cross-classification of Field Dependence/Independence with Giftedness, Sex, and Age

\begin{tabular}{|c|c|c|c|c|c|c|c|c|c|c|}
\hline \multirow[b]{2}{*}{ Group } & \multicolumn{5}{|c|}{ Age (years) of males } & \multicolumn{5}{|c|}{ Age (years) of females } \\
\hline & 9 & 10 & 11 & 12 & 13 & 9 & 10 & 11 & 12 & 13 \\
\hline \multicolumn{11}{|c|}{ Field dependent } \\
\hline Gifted & 2 & 2 & 1 & 2 & 1 & 5 & 2 & 0 & 0 & 1 \\
\hline Nongifted & 4 & 8 & 6 & 3 & 0 & 6 & 4 & 5 & 4 & 2 \\
\hline \multicolumn{11}{|c|}{ Field independent } \\
\hline Gifted & 11 & 16 & 13 & 17 & 5 & 11 & 11 & 10 & 14 & 3 \\
\hline Nongifted & 2 & 11 & 6 & 12 & 2 & 3 & 5 & 3 & 9 & 2 \\
\hline
\end{tabular}

and age is provided in Table 1. The gifted children in the sample were identified by the School Board during their 3rd grade year. To be selected they had to satisfy one of two conditions: (a) score in excess of the 95th percentile on the Canadian Test of Basic Skills or the Canadian Cognitive Abilities Test or (b) achieve, on the Canadian Test of Basic Skills and on the Canadian Cognitive Abilities Test, scores in the 90 to 95th percentile range, as well as "very superior" scores on the revised Weschler Intelligence Scale for Children.

\section{Testing Materials}

Our criterion task for field dependence/independence is the Children's Embedded Figures Test (Karp \& Konstadt, 1963; Witkin et al., 1962; Witkin \& Goodenough, 1981). Our group-administered version consists of two series of concrete, patterned and colored, drawings each of which contains, nested and "hidden" in it, a simple figure such as a triangle ("tent") or, in the second series, the outline of a house. A test item is scored correct (i.e., 1) only if the examinee traces the "hidden" figure. The estimated Cronbach's $\alpha$ internal consistency coefficient for this sample is moderate at .77. On the basis of his/her performance on the Children's Embedded Figures Test each subject's field dependence/ independence status will be determined using latent class analysis.

The criterion task for mental-attentional capacity is the Figural Intersection Task. The version used in the present study consists of a group administered paper-and-pen test. With a series of introductory test items the examinees are, step by step, taught all concepts and executive instructions needed in the task. These introductory test items show at most three intersecting shapes. This procedure of using learning as a control (DeAvila, 1976; DeAvila, Havassy, \& Pascual-Leone, 1976; Pascual-Leone, 1970; Pascual-Leone \& Smith, 1969) serves to reduce differences in know-how due to different experiential, educational, and social backgrounds of children, making the test more culturally fair. In this Figural Intersection Task, the number of relevant shapes on the left-hand side defines the item difficulty or mental demand of the test 
item; this number varied from 2 to 8 in the present study. There were 6 test items at each mental-demand level except at levels 2 and 8 (4 items) and 7 (7 items), for a total of 39 test items. An item is scored correct (i.e., 1) only if the examinee marks the area of common intersection in the figural compound, and the mark does not extend into another area, and there is no other mark on the figural compound (i.e., additional dots, outlines, etc.). In this study the child's mental power is derived from the Figural Intersection Task using a probabilistic scaling model (see below).

The Children's Embedded Figures Test and the Figural Intersection Task are both misleading tasks that involve a conflict between $\mathrm{X}$ - and $\mathrm{Y}$-strategies. In other respects, however, the two tasks are fundamentally different; for instance, in terms of the processes that generate a correct performance. In the Figural Intersection Task the mental demand level of items is carefully scaled, and systematically varied, to cover the expectable variation in mental attentional capacity of children. Further, using other measures of mental effort and/or chronological age as independent theory-predicted markers of a child's mental capacity (e.g., Fabian, 1982; Ho, 1994; Parkinson, 1995; Pascual-Leone, Baillargeon, Lee, \& Ho, 1991), it has been shown that a child will tend to pass an item of Figural Intersections Task only if the item's mental demand is below or equal to the child's mental power (except for false-positive errors). In contrast, items in Children's Embedded Figures Test are not scaled in their mental demand; they are merely chosen empirically to be accessible to the intended age group of children. Their mental demand is constant, or more or less equal to the child's expectable mental power. Items in an Embedded Figures task are empirically selected in terms of disembedding difficulty (degree of embeddedness or misleadingness). This is the difficulty with which a participant can identify the simple figure hidden/embedded into a complex drawing; and success is expected only if a child's X-strategies are more efficient than his/her Y-strategies.

\section{Statistical Method}

In the present study, multigroup latent structure analysis (Clogg \& Goodman, 1986) serves to distinguish group differences in mental-attentional capacity (mental power) from stylistic differences in mental processing strategies. Latent structure analysis investigates the dependence of manifest categorical variables on a small number of unobservable latent variables. When the latent variables under consideration can be regarded as discrete, the method is called latent class analysis. The latent class model (Lazarsfeld, 1954) assumes that associations among manifest variables can be explained by one or more latent variables, each constituted of one or more latent classes.

In our application, the manifest variables are dichotomous test items, and we postulate a single latent variable $X$ having $T(t=1,2, \ldots, T)$ latent classes. Each examinee is supposed to be in one of the mutually exclusive and exhaustive latent classes of this variable. The model assumes that items are mutually independent 
TABLE 2

Response Patterns Consistent with the Mental Demand/Mental Power Trade-Off

\begin{tabular}{cccccc}
\hline & \multicolumn{5}{c}{ Mental demand } \\
\cline { 2 - 5 } Mental power & 4 & 5 & 6 & 7 & 8 \\
\hline 3 & 0 & 0 & 0 & 0 & 0 \\
4 & 1 & 0 & 0 & 0 & 0 \\
5 & 1 & 1 & 0 & 0 & 0 \\
6 & 1 & 1 & 1 & 0 & 0 \\
7 & 1 & 1 & 1 & 1 & 1 \\
8 & 1 & 1 & 1 & & \\
\hline
\end{tabular}

Note. The numbers 1 and 0 represent success and failure on the tests items, respectively.

(i.e., assumption of local independence) within any single class of the latent variable.

The objective of this analysis of response patterns is to obtain estimates of two sorts of parameter: (a) unconditional latent class probabilities, $\pi_{t}$, the probability that a randomly selected examinee may be in latent class $t$; and (b) conditional item response probabilities, $\pi_{j \mid t}$, the probability of a correct response to item $j$ given the examinee's membership in latent class $t(t=1,2, \ldots, T)$. Consequently, $1-\pi_{j \mid t}$ is the probability of an incorrect response to item $j$ given the examinee's membership in latent class $t$. The unconditional latent class probabilities (i.e., $\pi_{t}$ ) must sum to 1 , and the conditional response probabilities (i.e., $\pi_{j \mid t}$ and $\left.1-\pi_{j \mid t}\right)$ must also sum to 1 within each latent class.

Latent class analysis can be used to assess the scalability of a set of dichotomous items. Consider a test made up of only five dichotomous items $(n=5)$, one for each mental demand level going from 4 to 8 . This is the format used in our data analysis. There are $2^{n}$ response patterns that are possible, i.e., 32 response patterns using five dichotomous items. Only $n+1$ of these patterns are consistent, however, with the principle of the mental demand/mental power trade-off presented above. The six consistent response patterns, one for each mental power level going from 3 to 8 , are presented in Table 2 . Note that in this case the test items form a Guttman scale (Guttman, 1950).

Let $t=$ mental power $=3,4, \ldots, 8$ denote the scale-type response patterns, under Guttman's deterministic model of scaling, which appear in the rows of Table 2. For a test made up of five items with mental-demand levels ranging from 4 to 8 , the mental demand/mental power trade-off, and hence Guttman's model, can be represented as a six-class latent structure model. This model assumes that the members of the $t$ th latent class have an "intrinsic" response pattern equal to that of scale-type $t(t=$ mental power $=3,4 \ldots, 8)$. Further, this model assumes that there is no measurement error and, consequently, the probability of a correct response is either 0 or 1 . Thus when the item's mental demand is above the 
child's mental power probability of a correct response should be equal to 0 , whereas it should equal 1 when the item's mental demand is below or equal the child's mental power. Nevertheless, due to conflict between the $\mathrm{X}$ - and the $\mathrm{Y}$-strategies, false-positive and false-negative response errors are expected to occur; and so response patterns other than these scale types will occur (PascualLeone \& Baillargeon, 1994).

A latent class model, Lazarsfeld's latent distance model (Dayton \& Macready, 1976; Lazarsfeld \& Henry, 1968) can adequately represent the mental demand/ mental power trade-off and account for the presence of false-positive and false-negative errors in the Figural Intersection Task (Pascual-Leone \& Baillargeon, 1994). Lazarsfeld's latent distance model is a probabilistic extension of Guttman's deterministic model which mathematically explains response errors as being due to measurement errors. For our subsets of data made up of five dichotomous items, one for each mental demand level (i.e., 4 to 8), Lazarsfeld's model is an unrestricted six-class model-each class comprising children whose mental power and expectable response pattern correspond, albeit probabilistically, to those found in the appropriate row of Table 2. Two kinds of parameters are estimated under Lazarsfeld's latent distance model: (a) the unconditional latent class probabilities, $\pi_{\mathrm{t}}(t=$ mental power $=3,4, \ldots, 8)$, that describe the distribution of the population over the mental power level; and (b) the conditional item response probabilities, $\pi_{j \mid t}(j=$ mental demand $=4,5, \ldots, 8$ and $t=$ mental power $=3,4, \ldots, 8$ ), that describe the way in which responses to each item depend on both the item's mental demand and the subject's mental power. In Lazarsfeld's model we estimate two conditional probabilities for each test item: One for the case when the item's mental demand is equal or below the child's mental power and another for when the item's mental demand is above the child's mental power. Thus the model is obtained by estimating for each item two response error rates (see Clogg \& Sawyer, 1981): (a) a false-positive error rate, $\alpha_{j t}$, which denotes the probability of a false-positive response error (i.e., a correct response to an item whose mental demand is above the child's mental power); and (b) a false-negative error rate, $\beta_{j t}$, which denotes the probability of a false-negative response error (i.e., an incorrect response on an item whose mental demand is below or equal to the child's mental power). Hence, the probability of a correct response to an item of mental demand $j$, for those examinees whose mental power is above or equal to the item's mental demand, is equal to $1-\beta_{j t}$. Similarly, the probability of an incorrect response to an item of mental demand $j$ for those examinees whose mental power is below the item's mental demand is equal to $1-\alpha_{j t}$. Due to the mathematical model it is not possible to estimate more than one response error rate for each of the two most extreme items - the easiest and most difficult item-(Lazarsfeld \& Henry, 1968, pp. 123-138).

The objective of multigroup latent structure analysis is twofold: (a) to determine whether the estimated latent class probabilities are homogeneous across 
groups of subjects (i.e., field independent versus field dependent) and (b) to determine whether the estimated item response probabilities are homogeneous across groups. This is done, respectively, by imposing intergroup homogeneity constraints on either the estimated latent class probabilities (i.e., $\pi_{t}$ are constrained to be equal across the groups) or the estimated item response probabilities (i.e., $\pi_{j \mid t}$ are constrained to be equal across the groups).

The multigroup latent class analysis was applied to the Figural Intersection Task data using a computer program for maximum-likelihood latent structure analysis written by the late Clifford C. Clogg (see Eliason, 1990; McCutcheon, 1987). To meet the DOS version program's matrix-size restrictions (no more than 300 cells) we have created four independent subsets of five test items. Each subset contains one item per mental demand level going from 4 to 8 . Note that items of mental demand 2 or 3 were not included in the analyses because they were passed (as theoretically predicted, Pascual-Leone \& Baillargeon, 1994) by almost all subjects in this sample (96\%).

\section{RESULTS}

The $\alpha$ level of significance (i.e., the probability of rejecting the null hypothesis when it is true) was set at .01 unless specified otherwise.

\section{Identification of the child's field dependence/independence cognitive style}

Before applying a multigroup latent class model to the Figural Intersection data children had to be classified as either field dependent or field independent on the basis of performance on the Children's Embedded Figures Test. To do so the unrestricted two-class model (Bergan, 1983; Dayton \& Macready, 1976; Goodman, 1974; Macready \& Dayton, 1977) was fit to the Children's Embedded Figures data. Such a model assumes that item performance can be explained by a single latent variable made of two mutually exclusive and exhaustive latent classes of children, a field-dependent and a field-independent class. In this model children in the field-dependent class are expected to fail all items, whereas those in the field-independent class would succeed. Under this model response patterns which don't reflect either totally correct or totally incorrect performances are explained in terms of measurement error (i.e., false-positive and false-negative error rates). Only children's responses to seven test items (with less than $90 \%$ of the subjects answered correctly) will be considered here, since other items carry little differential information on examinees.

The value of the likelihood ratio $\chi^{2}\left(L^{2}\right)$ associated with the unrestricted two-class model is 96.29 with 112 degrees of freedom $(p<.86)$. Hence, the unrestricted two-class model fits very well the Children's Embedded Figures data suggesting the two predicted groups. Moreover, this represents a decrease of 111.96 in $L^{2}$ with a corresponding decrease of 8 degrees of freedom from the model of mutual independence among the test items $\left(L^{2}=208.25-\right.$ $96.29=111.96, d f=120-112=8, p<.00)$. Since this decrease is large 
compared to the decrease in the degrees of freedom, there is indication that the two-class unrestricted model is a real improvement of fit over the mutual independence model.

Thus far we have established that children are all concentrated in two homogeneous latent classes corresponding roughly to the two poles of the field dependence/independence cognitive style. We are now in a position to infer from their observed response patterns the children's latent state depending upon whether they are field dependent or field independent. The assignment of subjects to latent classes follows a procedure described by Clogg (1979). Of a total of 224 subjects, 58 and 166 were assigned respectively to the field-dependent and field-independent latent classes. Note that $92 \%$ of children are correctly classified into the latent classes. This coefficient indicates an excellent ability to predict the child's latent class from his or her observed response pattern (Clogg, 1979, 1981).

Before attempting to compare the performance of the two groups (i.e., field dependent versus field independent) on the Figural Intersection Task, we look at the relationships between field dependence/independence, sex, age, and giftedness. Table 1 presents the cross-classification of field dependence/independence with sex, giftedness, and age. The relationships among the variables in the four-way cross-classification can be investigated using log-linear models. First, consider a log-linear model which contains first- and second-order effects. This model yields a $L^{2}$ of 12.25 on 17 degrees of freedom $(p<.79)$. Moreover, this represents a decrease of 46.87 in $L^{2}$ with a corresponding decrease of 15 degrees of freedom from the independence model $\left(L^{2}=59.12-12.25=46.87, d f=\right.$ $32-17=15, p<.00)$. Thus, a model with first- and second-order effects seems adequate to represent the relationships among these variables. Next, the contribution of each individual second-order effect was evaluated. Among the various second-order effects only the field dependence/independence by giftedness effect has reached significance $\left(\chi^{2}=31.48, d f=1, p<.00\right)$. There is a very significant association between field dependence/independence and giftedness-overall, the estimated odds under the saturated hierarchical log-linear model of being field independent are 4.33 times higher for gifted than for nongifted children. ${ }^{1}$ At the same time, we cannot reject the null hypotheses of no association between field dependence/independence and age $\left(\chi^{2}=11.64, d f=4, p<.02\right)$ or field dependence/independence and $\operatorname{sex}\left(\chi^{2}=.63, d f=1, p<.43\right)$.

The apparent lack of association in our study between field dependence/ independence and age, surprising in the light of some empirical developmental findings, is consistent with our theory: The mental demand of the Children's Embedded Figures Test is below the predicted age-bound mental capacity of our sample and so the task may be too easy to exhibit a strong developmental trend (Pascual-Leone \& Goodman, 1979).

${ }^{1}$ These odds can also be estimated, albeit less precisely, from data of Table 1 . In this manner the odds ratio is 5.4 . 
The significant association between field dependence/independence and giftedness might, arguably, call into question the bipolar, value-differentiated character of field dependence/independence as a latent variable determining performance on Children's Embedded Figures Test. This value-differentiated character will be supported, however, if these two predictions are born out: (1) Fielddependent children tend to do better than field-independent children whenever the situation is misleading (as in the Figural Intersection Task) and the item's mental demand is above the child's mental power. (2) Field-independent children tend to do better than field-dependent children whenever the item's mental demand is equal to or below the child's mental power.

Before presenting these results we must establish that items within classes have the same difficulty and that no significant intratask learning occurs that makes a difference in performance on items from the same class that are situated far apart in the testing sequence. The next short section is devoted to this test.

\section{Validating a priori estimates of items' mental demand in the figural intersections task}

The number of relevant shapes overlapping in a common intersection defines an item's mental demand in the Figural Intersections Task. Test items of the same mental demand are hypothesized to have the same difficulty, no matter what their order of appearance in the test or the degree of practice examinees have had in solving them. Examinees should tend to fail or succeed together all test items that exhibit the same mental demand. Consequently, hypotheses of equal difficulty and no practice effects can be tested using a two-class model if we impose equality constraints on the estimated item-response probabilities across items with equal mental demand, which are used to compare the performance of field-dependent and field-independent children on the Figural Intersection Task.

This restricted two-class model yields an $L^{2}$ of 78.92 with 114 degrees of freedom for the four test items of mental demand equal to 4 . This represents an increase of 16.50 in $L^{2}$ with a corresponding increase of 11 degrees of freedom from the unrestricted two-class model $(p<.12)$. Since this increase is relatively small compared to the increase in the degrees of freedom, we conclude that our test items comprising four geometric shapes tend to be of the same difficulty [i.e., the same probability of a correct response to test item $j$ given the examinee's membership in latent class $t(t=1,2)]$. Furthermore, this finding is replicated in others sets: with items of mental demand equal to $5\left(L^{2}=117.67-104.23=\right.$ $13.45, d f=112-100=12, p<.34)$, mental demand equal to $6\left(L^{2}=123.8-\right.$ $109.33=14.47, d f=112-101=11, p<.21)$, mental demand equal to $7\left(L^{2}\right.$ $=193.84-178.95, d f=236-124=12, p<.25$, and mental demand equal to $8\left(L^{2}=20.50-15.29=5.21, d f=24-12=12, p<.95\right)$.

Thus our test items of the same mental demand tend to have the same difficulty, independent of their order of appearance in the Figural Intersection Task. More importantly, these results constitute a validation of our prior estimate 
of the items' mental demand in terms of the number of relevant shapes overlapping on the common intersection. Indeed, since items of the same mental demand have equal difficulty, and the classes of items are ordered in difficulty as predicted (making allowance for type A and type B errors, so that probabilistic equivalents of the Guttman model fit these data well), we have a powerful test of our a priori estimates of items' mental demand.

\section{Comparing the performance of field dependent versus field independent children on the figural intersection task}

Table 3 contains the response patterns, and corresponding observed frequencies of occurrence, for the four subsets of five test items. The relative frequencies associated with the 32 response patterns differ substantially from one group to the other. Consider, for instance, the odds of producing a perfect performance (i.e., 11111) in the first subset of five test items. For the field-independent children the odds are 58 to 108 , namely, .54. In contrast, for the field-dependent children the odds are only .14 (7/51). Hence, the odds of answering correctly all five test items are almost four times higher for the field-independent than for the field-dependent children. A similar pattern is present in the second, third, and fourth subsets of five items. Generally field-independent children seem to perform much better than field-dependent children.

Within the framework of multigroup latent class analysis, these differences between field-dependent and field-independent children, in frequencies associated with observed response patterns, could arise from two very different sources. The first possible explanation is that (regardless of whether we consider the latent class probabilities to be the same or not in both groups) the item response probabilities are not the same for both groups. If this were the case the finding could be consistent with our theoretical model, which states that fielddependent people differ from field-independent ones in the strength of various organismic factors responsible for performance in misleading situations. The second possible explanation is that, regardless of whether we consider item response probabilities to be the same or not for both groups, latent class probabilities are not the same for both groups. That is, field-dependent people could differ from field-independent people in their rate of progression through the mental power levels-as assessed by the Figural Intersection Task.

Consider now the multigroup scaling model that will later be used to compare the two groups by imposing intergroup homogeneity constraints on the parameter estimates. In a previous study, Pascual-Leone and Baillargeon (1994) found that the Lazarsfeld's latent distance model was theoretically suitable and fit well the Figural Intersection Task data. In the present study this result is less clear, although consistent. The value of the likelihood ratio $\chi^{2}$ statistic associated with Lazarsfeld's latent distance model for the first subset of five test items is 23.53 with 40 degrees of freedom $(p<.98)$. Hence, Lazarsfeld's latent distance model seems to provide an excellent fit to the data for the first subset of five test items. 
TABLE 3

Observed Frequencies of Response Patterns in Four Five-Item Subsets for the Field-Independent and Field-Dependent (in Brackets) Groups

\begin{tabular}{|c|c|c|c|c|c|}
\hline Index & $\begin{array}{l}\text { Response } \\
\text { pattern }\end{array}$ & $\begin{array}{c}\text { First } \\
\text { subset }\end{array}$ & $\begin{array}{l}\text { Second } \\
\text { subset }\end{array}$ & $\begin{array}{l}\text { Third } \\
\text { subset }\end{array}$ & $\begin{array}{l}\text { Fourth } \\
\text { subset }\end{array}$ \\
\hline 1 & 00000 & 05 [04] & 01 [06] & 03 [05] & 05 [07] \\
\hline 2 & 10000 & $02[06]$ & 04 [04] & $06[10]$ & 05 [05] \\
\hline 3 & 01000 & 01 [02] & $00[01]$ & $02[00]$ & $02[01]$ \\
\hline 4 & 11000 & 10 [09] & 15 [02] & 04 [03] & 06 [06] \\
\hline 5 & 00100 & $00[00]$ & $02[01]$ & 00 [02] & $00[00]$ \\
\hline 6 & 10100 & 03 [02] & 01 [02] & 04 [02] & 03 [05] \\
\hline 7 & 01100 & $00[00]$ & $00[01]$ & $00[00]$ & $01[02]$ \\
\hline 8 & 11100 & 13 [06] & 13 [04] & 12 [07] & $21[06]$ \\
\hline 9 & 00010 & 00 [02] & $00[01]$ & $00[00]$ & $00[00]$ \\
\hline 10 & 10010 & 01 [03] & 00 [03] & $02[00]$ & 03 [01] \\
\hline 11 & 01010 & $00[00]$ & 02 [00] & $01[01]$ & 01 [00] \\
\hline 12 & 11010 & 07 [02] & 07 [01] & 03 [05] & 04 [03] \\
\hline 13 & 00110 & $00[00]$ & $00[00]$ & $00[01]$ & $01[00]$ \\
\hline 14 & 10110 & 07 [01] & 03 [02] & 04 [01] & 04 [03] \\
\hline 15 & 01110 & $01[00]$ & 00 [01] & $02[01]$ & $00[00]$ \\
\hline 16 & 11110 & $40[07]$ & 40 [17] & $46[05]$ & $40[07]$ \\
\hline 17 & 00001 & $00[00]$ & $00[00]$ & $00[00]$ & $00[00]$ \\
\hline 18 & 10001 & 00 [00] & $00[00]$ & $02[00]$ & $00[01]$ \\
\hline 19 & 01001 & $00[00]$ & $00[01]$ & $00[00]$ & $00[00]$ \\
\hline 20 & 11001 & 01 [01] & $02[01]$ & $06[01]$ & $02[01]$ \\
\hline 21 & 00101 & 00 [00] & $00[00]$ & $00[00]$ & $00[00]$ \\
\hline 22 & 10101 & $00[00]$ & $00[00]$ & 01 [01] & $02[00]$ \\
\hline 23 & 01101 & $00[00]$ & 00 [01] & $01[00]$ & $00[00]$ \\
\hline 24 & 11101 & 11 [03] & 08 [01] & 05 [02] & $05[01]$ \\
\hline 25 & 00011 & $00[00]$ & $00[01]$ & 00 [01] & $00[00]$ \\
\hline 26 & 10011 & 00 [01] & $00[00]$ & $00[00]$ & $02[01]$ \\
\hline 27 & 01011 & $00[00]$ & $00[00]$ & $00[00]$ & $01[00]$ \\
\hline 28 & 11011 & $05[02]$ & 04 [02] & 07 [03] & 09 [03] \\
\hline 29 & 00111 & $00[00]$ & $00[00]$ & $00[00]$ & $00[00]$ \\
\hline 30 & 10111 & $01[00]$ & $02[00]$ & $05[00]$ & $01[02]$ \\
\hline 31 & 01111 & $00[00]$ & $01[00]$ & $02[00]$ & $01[00]$ \\
\hline 32 & 11111 & $58[07]$ & $61[05]$ & 48 [07] & $47[03]$ \\
\hline - & All patterns & $166[58]$ & $166[58]$ & $166[58]$ & $166[58]$ \\
\hline
\end{tabular}

Note. The numbers 1 and 0 indicate a correct and an incorrect response, respectively. The sequence of responses in each pattern is for items with, respectively, mental demand of 4, 5, 6, 7, and 8. Subset 1 consists of items numbered (in the FIT) 14, 4, 6, 33, and 9, respectively; subset 2, items 3, 11, 24a, 7, and 12; subset 3, items 38, 15, 32, 36, and 22; and subset 4, items 35, 29, 27, 20 and 31 .

Furthermore, this finding is replicated in the second $\left(L^{2}=36.11, d f=36, p<\right.$ $.46)$, third $\left(L^{2}=38.43, d f=38, p<.45\right)$, and fourth $\left(L^{2}=29.83, d f=39, p<\right.$ .86) subsets of five test items. As further evidence of the good fit of Lazarsfeld's latent distance model to the Figural Intersection data note that this model 
explains a full $89,83,80$, and $84 \%$ of the variances in the first, second, third, and fourth subsets of five test items, respectively.

However, a simplified version of Lazarsfeld's latent distance model, the Item-specific error rate model (Clogg \& Sawyer, 1981), could provide an empirically simpler explanation of these Figural Intersection Task data-one that requires the estimation of fewer parameters. It is a restricted six-class latent structure model which assumes that there is a single response error rate for each test item. In other words, this model assumes that, for each item, the probability of a false-positive error is equal to the probability of a false-negative error. The value of the likelihood ratio $\chi^{2}\left(L^{2}\right)$ associated with the Item-specific error rate model for the first subset of five test items is 29.19 with 43 degrees of freedom $(p<.95)$. This represents an increase of 5.65 in $L^{2}$ with a corresponding increase of 3 degrees of freedom from Lazarsfeld's latent distance model $\left(L^{2}=29.19-\right.$ $23.53=5.65, d f=43-40=3, p<.13)$. Since this increase in $L^{2}$ is small compared to the increase in degrees of freedom, this indicates that the additional parameters in Lazarsfeld's latent distance model do not produce an improvement of fit. Moreover, the item-specific error rate model doesn't represent a significant decrement of fit over Lazarsfeld's latent distance model in the second $\left(L^{2}=\right.$ $42.78-36.11=6.67, d f=42-36=6, p<.35)$, third $\left(L^{2}=41.41-38.43=\right.$ $2.98, d f=43-38=5, p<.70)$, and fourth $\left(L^{2}=34.90-29.83=5.08, d f=\right.$ $44-39=5, p<.41)$ subsets of five test items. Thus, even though Lazarsfeld's latent distance model is a theoretically more appropriate model for the Figural Intersection Task (Pascual-Leone \& Baillargeon, 1994) we adopt here the Itemspecific error rate model for the sake of computational simplicity without loss of generality.

Table 4 gives the parameter values estimated for the four subsets of five items under the item-specific error rate model, with no intergroup homogeneity constraints on the parameters estimates. The parameters values are the estimated latent class probabilities (i.e., $\pi_{t}$ ) and the estimated conditional probabilities of a correct item response (i.e., $\pi_{j \mid t}$ ).

Inspection of Table 4 reveals consistent individual differences in the probabilities of a correct item response. With few exceptions, field-dependent children consistently have a higher probability of success than field-independent children when the item's mental demand is above the child's mental power (see Table 4). This counterintuitive finding confirms (a test of statistical significance will be presented below) the first hypothesis of the study. According to this first theoretical prediction, whenever mental demand in misleading tasks is greater than the child's mental power, the strong contextual Y-strategies characteristic of field-dependent children give them advantage over field-independent children. In items where mental demand is below or equal to the child's mental power, field-independent children have a higher probability of success than field-dependent children (see Table 4). This second finding confirms, at least partially, the second hypothesis of this study (i.e., strong executive-driven $\mathrm{X}$-strategies of field-independent children give them a definite 
TABLE 4

Parameter Estimates for the Four Subsets of Five Items Using the Multigroup Item-Specific Error Rate Model for the Field-Independent and Field-Dependent (in Brackets) Groups

Latent class $t$ (mental power)

\begin{tabular}{llllllll}
\cline { 3 - 8 } Parameter & Subset & 3 & 4 & 5 & 6 & 7 & 8 \\
\hline
\end{tabular}

$\pi_{t}$

$\begin{array}{lllllll}1 & .04[.14] & .01[.18] & .08[.20] & .05[.10] & .37[.15] & .46[.24] \\ 2 & .02[.19] & .02[.14] & .12[.03] & .05[.01] & .33[.52] & .47[.12] \\ 3 & .02[.15] & .06[.25] & .06[.01] & .11[.18] & .33[.21] & .41[.20] \\ 4 & .05[.17] & .05[.14] & .01[.10] & .15[.19] & .33[.25] & .42[.15]\end{array}$

$\pi_{4 \mid t}$

$\begin{array}{lllllll}1 & .01[0.0] & .99[1.0] & .99[1.0] & .99[1.0] & .99[1.0] & .99[1.0] \\ 2 & .02[.09] & .98[.92] & .98[.92] & .98[.92] & .98[.92] & .98[.92] \\ 3 & .05[.06] & .95[.94] & .95[.94] & .95[.94] & .95[.94] & .95[.94] \\ 4 & .03[0.0] & .97[1.0] & .97[1.0] & .97[1.0] & .97[1.0] & .97[1.0]\end{array}$

$\pi_{5 \mid t}$

$\begin{array}{lllllll}1 & .08[.13] & .08[.13] & .92[.87] & .92[.87] & .92[.87] & .92[.87] \\ 2 & .04[.11] & .04[.11] & .96[.89] & .96[.89] & .96[.89] & .96[.89] \\ 3 & .10[0.0] & .10[0.0] & .90[1.0] & .90[1.0] & .90[1.0] & .90[1.0] \\ 4 & .10[.31] & .10[.31] & .90[.69] & .90[.69] & .90[.69] & .90[.69]\end{array}$

$\pi_{6 \mid t}$

$\begin{array}{lllllll}1 & .09[.16] & .09[.16] & .09[.16] & .91[.84] & .91[.84] & .91[.84] \\ 2 & .11[.13] & .11[.13] & .11[.13] & .89[.87] & .89[.87] & .89[.87] \\ 3 & .10[.34] & .10[.34] & .10[.34] & .90[.66] & .90[.66] & .90[.66] \\ 4 & .16[.31] & .16[.31] & .16[.31] & .84[.69] & .84[.69] & .84[.69]\end{array}$

$\pi_{7 \mid t}$

$\begin{array}{lllllll}1 & .15[.25] & .15[.25] & .15[.25] & .15[.25] & .85[.75] & .85[.75] \\ 2 & .12[.24] & .12[.24] & .12[.24] & .12[.24] & .88[.76] & .88[.76] \\ 3 & .05[.14] & .05[.14] & .05[.14] & .05[.14] & .96[.86] & .95[.86] \\ 4 & .13[0.0] & .13[0.0] & .13[0.0] & .13[0.0] & .87[1.0] & .87[1.0]\end{array}$

$\pi_{8 \mid t}$

\begin{tabular}{lllllll}
1 & $.002[.01]$ & $.002[.01]$ & $.002[.01]$ & $.002[.01]$ & $.002[.01]$ & $.998[.99]$ \\
2 & $.03[.12]$ & $.03[.12]$ & $.03[.12]$ & $.03[.12]$ & $.03[.12]$ & $.98[.88]$ \\
3 & $.29[.09]$ & $.29[.09]$ & $.29[.09]$ & $.29[.09]$ & $.29[.09]$ & $.71[.91]$ \\
4 & $.002[.09]$ & $.002[.09]$ & $.002[.09]$ & $.002[.09]$ & $.002[.09]$ & $.998[.91]$ \\
\hline
\end{tabular}

Note. The MLLSA program was unable to estimate some of the conditional probabilities and fixed them to values of either 1 or $0 . \pi_{t}(t=$ Mental power $3,4, \ldots, 8)$ is the probability that a randomly selected examinee be in latent class $t$. The value of $\pi_{j \mid t}(j=$ Mental demand $=4,5, \ldots, 8$ and $t=$ Mental power $=3,4, \ldots, 8$ ) is the probability of a correct response to item $j$ given the examinee's membership in latent class $t$. 
advantage over field-dependent children when the task's mental demand is equal to or smaller than the subject's mental power). The statistical significance of these differences between the two groups (field dependent versus field independent) can be tested by imposing intergroup homogeneity constraints on the estimated item response probabilities. This gives an increase of 3.80 in $L^{2}$ with a corresponding increase of 4 degrees of freedom for the first subset of five test items $\left(L^{2}=32.99-\right.$ $29.19=3.80, d f=47-43=4, p<.43$ ). Therefore, the hypothesis of intergroup homogeneity in the estimated probabilities of a correct item response cannot be rejected for the first subset of five test items. However, the hypothesis of intergroup homogeneity in the estimated item response probabilities is rejected $(\alpha=.10)$ in the second $\left(L^{2}=52.41-42.78=9.63, d f=47-42=5, p<.09\right)$, third $\left(L^{2}=\right.$ $55.29-41.41=13.88, d f=47-43=4, p<.01)$, and fourth $\left(L^{2}=49.02-\right.$ $34.90=14.13, d f=47-44=3, p<.00)$ subsets of five items. The finding seems to suggest that a child's field dependent/independent style of functioning enhances or interferes with performance (in misleading situations like the Figural Intersection Task), depending upon the kind of mental demand/mental power trade-off.

Further inspection of Table 4 shows consistent individual differences in the estimated latent class probabilities (i.e., $\pi_{t}$ ). Field-dependent children have a greater probability than field-independent children to belong to the lower levels of mental power. In contrast, field-dependent children show smaller probability than field-independent children to belong to the higher mental power levels. Consider the estimated latent class probabilities for the first subset of five items. The odds of belonging to the lowest mental power level (i.e., mental power $=3$ ) are more than 4 times higher for the field-dependent than for the field-independent subjects $[(.14 / .86) /(.04 / .96)=4.37]$. Similarly, the odds are 16.07, 2.96, and 2.27 times higher for field-dependent than for field-independent children to belong to mental power levels 4,5 , and 6 , respectively. We observe, however, the opposite pattern for the highest and second highest mental power levels. The odds of belonging to mental power levels 7 and 8 are, respectively, 3.32 and 2.70 times higher for the field-independent children than for the field-dependent children.

The statistical significance of these differences in the estimated latent class probabilities between the two groups (field dependent versus field independent) can be tested by imposing intergroup homogeneity constraints on the estimated latent class probabilities. This gives 37.44 with 6 degrees of freedom $\left(L^{2}=66.63-29.19=37.44, d f=49-43=6, p<.00\right)$ for the first subset of five test items. Since this decrease in $L^{2}$ is very large compared to the decrease in the degrees of freedom, we reject at the .01 level the hypothesis that the estimated proportion of children in the various mental power levels is the same in the two groups. Furthermore, the hypothesis of intergroup homogeneity in the latent class probabilities is also rejected in the second $\left(L^{2}=86.57-42.78=43.79, d f=47-42=5, p<.00\right)$, third $\left(L^{2}\right.$ $=74.70-41.41=33.29, d f=48-43=5, p<.00)$, and fourth $\left(L^{2}=\right.$ 
$67.10-34.90=32.20, d f=49-44=5, p<.00)$ subset of five test items. This finding indicates that field-dependent children obtain estimates of mental power levels much lower than those of their field-independent counterparts in misleading situations like the Figural Intersections Task.

\section{GENERAL DISCUSSION}

The results from multigroup latent class analyses show consistent individual differences between field-dependent and field-independent children.

As predicted, field-dependent children have better odds of success than fieldindependent children when the task's mental demand is above the child's mental power-and Y-strategies dominate X-strategies (Pascual-Leone \& Baillargeon, 1994). The contrary is true when the task's mental demand is below or equal to the child's mental power, so that X-strategies dominate Y-strategies (PascualLeone \& Baillargeon, 1994). Thus, in a situation like the Figural Intersection Task neither pole of the field dependence/independence style is uniformly good or bad for performance.

More evidence of the bipolar character of field dependence/independence cognitive style (Johnson \& Rosano, 1993; Messick, 1987; Pascual-Leone, 1969, 1989; Pascual-Leone \& Morra, 1991; Witkin \& Goodenough, 1981) appears by comparing performance of nongifted versus gifted children on the Figural Intersection Task using multigroup latent structure analysis. The results show that gifted children tend to have better odds of success than nongifted children, irrespective of whether the item's mental demand is above, below, or equal to the child's mental power. This is always the case in our data whenever estimates of the item response probabilities were available to make the comparison under Lazarsfeld's latent distance model. Hence, although nongifted children are over five times more likely to be field dependent than gifted children, they don't perform as well as field-dependent children do in misleading situations like Figural Intersection Task. This contrast supports the distinction between cognitive abilities and cognitive styles that we made earlier. Namely, field dependence/ independence (when assessed as latent variable using Children's Embedded Figures Test) appears in the Figural Intersection task as a bipolar, valuedifferentiated construct; but the nongifted/gifted distinction appears as unipolar and value directional.

Such findings also give support to Pascual-Leone's model of field dependence/ independence (DeRibaupierre, 1989; Globerson, 1989; Pascual-Leone, 1969, 1989; Pascual-Leone \& Baillargeon, 1994; Pennings, 1988). The model postulates that individual differences in mental-attentional resources may underlie the "categorical," bipolar dimensionality of this cognitive style (see Messick, 1993a, for a recent review of literature supporting this claim). According to this model, field-dependent people have relatively inefficient mental capacity (M) and attentional interrupt (I), but exhibit strong content learning (C learning), structural overlearning (LC learning), and Gestaltist field (or F) factors. Because the latter 
organismic factors must be used to solve a task whose mental demand is above the subject's mental power, field-dependent people might perform better than field-independent ones in this situation. In contrast, field-independent subjects are assumed to have strong organismic factors of mental capacity and attentional interrupt, but often weaker C, LC, and F factors. Because correct performance in misleading situations requires both active inhibition (interruption) of task-irrelevant schemes, and the attentional boosting of task-relevant schemes, fieldindependent subjects might perform better than field-dependent subjects whenever a task's mental demand is below or equal to the subject's mental power.

Consistent with this theory we have found, replicating previous results (e.g., Pascual-Leone, 1969, 1989; Pascual-Leone \& Morra, 1991), that field-independent children exhibit superior mental-attentional capacity in nonautomatized misleading tasks such as the Figural Intersection Task. As a moderator variable intervening in the manifestation of cognitive abilities, the cognitive style of field dependence/independence may favor field-independent subjects in misleading situations; it may be because strong X-strategies foster the growth of sophisticated executive schemes. Since executive schemes are responsible for mobilizing and allocating the child's mental-attentional resources (i.e., mental energy and mental interrupt) the lack of sophisticated executive schemes in field-dependent subjects may reduce their ability to generate successful "truly novel" performances in misleading situations. Truly novel performances are performances "that are not implicitly or explicitly represented in the subject's repertoire of habitual schemes" (Pascual-Leone \& Morra, 1991, p. 261). This suggests that by limiting the complexity of performatory syntheses that field-dependent subjects can generate, the field dependence/independence cognitive style can influence not only the manner but also the level of effortful processing that subjects exhibit in misleading situations (Brodzinsky, 1985; Messick, 1984, 1987, 1993b; Pascual-Leone, 1970; Zelniker, 1989). But this interpretation still needs more validation across types of mental-attentional capacity tasks that differ in their degree of misleadingness. Such a theoretical view is consistent with PascualLeone's thesis (Pascual-Leone, 1969), 1970, 1989) that "hidden" mental-attentional capacity (i.e., the growth of mental power and mental interrupt) of field-dependent people is comparable to that of field-independent people; fielddependent children might perform less well than field-independent ones because in misleading situations they mobilize and allocate inadequately their age-normal mental attentional capacity. This characteristic of field-dependent people might well be caused by a "functional" executive deficiency rather than a "structural" developmental capacity deficiency (Pascual-Leone, 1970).

\section{REFERENCES}

Bergan, J. R. (1983). Latent-class models in educational research. In E. W. Gordon (Ed.), Review of research in education (Vol. 10, pp. 305-360). Washington, DC: American Educational Research Association.

Brodzinsky, D. M. (1985). On the relationship between cognitive styles and cognitive structures. In 
E. D. Neimark, R. De Lisi, \& J. L. Newman, (Eds.), Moderators of competence (pp. 147-174). Hillsdale, NJ: Erlbaum.

Clogg, C. C. (1979). Some latent structure models for the analysis of Likert-type data. Social Science Research, 8, 287-301.

Clogg, C. C. (1981). New developments in latent structure analysis. In D. M. Jackson \& E. F. Borgatta (Eds.). Factor analysis and measurement in sociological research (pp. 215-246). Beverly Hills, CA: Sage.

Clogg, C. C., \& Goodman, L. A. (1986). On scaling models applied to data from several groups. Psychometrika, 51, 123-135.

Clogg, C. C., \& Sawyer, D. O. (1981). A comparison of alternative models for analyzing the scalability of response patterns. In S. Leinhardt (Ed.), Sociological methodology (pp. 240-280). San Francisco, CA: Jossey-Bass.

Dayton, C. M., \& Macready, G. B. (1976). A probabilistic model for the validation of behavioral hierarchies. Psychometrika, 41, 189-204.

DeAvila, E. A. (1976) Mainstreaming ethnically and linguistically different children: An exercise in paradox or a new approach? In R. L. Jones (Ed.), Mainstreaming and the minority children (pp. 93-108). Minneapolis, MN: Leadership Training Institute/Special Education.

DeAvila, E. A., Havassy, B. H., \& Pascual-Leone, J. (1976) Mexican-American school children: A neo-Piagetian analysis. Washington, DC: Georgetown University Press.

DeRibaupierre, A. (1989). Cognitive style and operational development: A review of the French literature and a neo-Piagetian reinterpretation. In T. Globerson \& T. Zelniker (Eds.), Cognitive style and cognitive development (pp. 86-115). Norwood, NJ: Human Development Series.

DeRibaupierre, A., \& Pascual-Leone, J. (1979). Formal operations and M power: A neo-Piagetian investigation. In D. Kuhn (Ed.), New directions for child development (Vol. 5, pp. 1-43). San Francisco, CA: Jossey-Bass.

Eliason, S. R. (1990). The categorical data analysis system. User's manual (Version 3.5) [Computer program]. University of Iowa.

Fabian, V. (1982). Language development after 5: A neo-Piagetian investigation of subordinate conjunctions. Unpublished doctoral dissertation, University of California, Berkeley.

Globerson, T. (1985). Field dependence/Independence and mental capacity: A developmental approach. Developmental Review, 5, 261-273.

Globerson, T. (1983). Mental capacity, mental effort, and cognitive style. Developmental Review, 3, 292-302.

Globerson, T. (1989). What is the relationship between cognitive style and cognitive development. In T. Globerson and T. Zelniker (Eds.), Cognitive style and cognitive development (pp. 71-85). Norwood, NJ: Ablex.

Globerson, T., \& Zelniker, T. (Eds, 1989). Cognitive style and cognitive development. Norwood, NJ: Ablex.

Goodman, L. A. (1974). The analysis of systems of qualitative variables when some of the variables are unobservable. Part 1: Modified latent structure approach. American Journal of Sociology, 79, 1179-1259.

Guttman, L. (1950). The basis for scalogram analysis. In S. A. Stouffer, L. Guttman, E. A. Suchman, P. F. Lazarsfeld, S. A. Star, \& J. A. Clausen (Eds.), Measurement and prediction: Studies in social psychology in World War II (Vol. 4, pp. 60-90). Princeton, NJ: Princeton University Press.

Hasher, L., \& Zacks, R. T. (1979). Automatic and effortful processes in memory. Journal of Experimental Psychology: General, 106, 356-388.

Ho, G. W. (1994). Core sample analysis of developmental traces: A neo-Piagetian study of M-capacity tasks. Unpublished MA thesis, York University, Toronto.

Johnson, J., \& Rosano, T. (1993). Relations of cognitive style to metaphor interpretation and second language proficiency. Applied Psycholinguistics, 14, 159-175.

Kahneman, D. (1973). Attention and effort. Englewood Cliffs, NJ: Prentice-Hall. 
Karp, S. A., \& Konstadt, N. I. (1963). Children's embedded figures test. New York: Cognitive Tests. Lazarsfeld, P. F. (1954). A conceptual introduction to latent structure analysis. In P. F. Lazarsfeld (Ed.), Mathematical thinking in the social sciences (pp. 349-387). Glencoe, IL: The Free Press. Lazarsfeld, P. F., \& Henry, N. W. (1968). Latent structure analysis. Boston: Houghton Mifflin.

Linn, M. C. (1978). Influence of cognitive style and training on tasks requiring their separation of variables schema. Child Development, 49, 874-877.

Macready, G. B., \& Dayton, C. M. (1977). The use of probabilistic models in the assessment of mastery. Journal of Educational Statistics, 2, 99-120.

McCutcheon, A. L. (1987). Latent class analysis. Sage University Paper series on Quantitative Applications in the Social Sciences, Beverly Hills, CA: Sage.

Messick, S. (1984). The nature of cognitive styles: Problems and promise in educational practice. Educational Psychologist, 19, 59-74.

Messick, S. (1987). Structural relationships across cognition, personality, and style. In R. E. Snow \& M. J. Farr (Eds.), Aptitude, learning, and instruction: Conative and affective process analyses (Vol. III, pp. 35-75). Hillsdale, NJ: Erlbaum.

Messick, S. (1993a). Human abilities and modes of attention: The issue of stylistic consistencies in cognition. Research Report (RR-93-43). Princeton, NJ: Educational Testing Service.

Messick, S. (1993b). The matter of style: Manifestations of personality in cognition, learning, and teaching. Research Report (RR-93-44). Princeton, NJ: Educational Testing Service.

Neimark, E. D. (1981). Confounding with cognitive style factors: An artifact explanation for the apparent nonuniversal incidence of formal operations. In I. E. Siegel, D. M. Brodzinsky, \& R. M. Golinkoff (Eds.), New directions in Piagetian theory and practice (pp. 177-189). Hillsdale, NJ: Erlbaum.

Neimark, E. D. (1985). Moderators of competence: Challenges to the universality of Piagetian theory. In E. D. Neimark, R. De Lisi, \& J. L. Newman (Eds.), Moderators of competence (pp. 1-14). Hillsdale, NJ: Erlbaum.

Parkinson, G. M. (1975). The limits of learning: A quantitative investigation of intelligence. Unpublished doctoral dissertation. York University, Toronto.

Pascual-Leone, J. (1969). Cognitive development and cognitive style: A general psychological integration. Unpublished doctoral dissertation. University of Geneva.

Pascual-Leone, J. (1970). A mathematical model for the transition rule in Piaget's developmental stages. Acta Psychologica, 32, 301-345.

Pascual-Leone, J. (1980). Constructive problems for constructive theories: The current relevance of Piaget's work and a critique of information-processing simulation psychology. In R. Kluwe \& H. Spada (Eds.), Developmental models of thinking (pp. 263-296). New York: Academic Press.

Pascual-Leone, J. (1984). Attention, dialectic, and mental effort: Toward an organismic theory of life stages. In M. L. Commons, F. A. Richards, \& G. Armon (Eds.), Beyond formal operations: Late adolescent and adult cognitive development (pp. 182-215). New York: Praeger.

Pascual-Leone, J. (1987). Organismic processes for neo-Piagetian theories: A dialectical causal account of cognitive development. In A. Demetriou (Ed.), The neo-Piagetian theories of cognitive development: Towards an integration (pp. 531-569). Amsterdam: North-Holland.

Pascual-Leone, J. (1989). An organismic process model of Witkin's field-dependence/independence. In T. Globerson \& T. Zelniker (Eds.), Cognitive style and cognitive development (pp. 36-70). Norwood, NJ: Human Development Series.

Pascual-Leone, J. (1995). Learning and development as dialectical factor in cognitive growth. Human Development, 38, 338-348.

Pascual-Leone, J. (1997). Metasubjective processes: The missing "lingua franca" of cognitive science. In D. Johnson and C. Erneling (Eds.), The future of the cognitive revolution (pp. 75-101). New York: Oxford University Press.

Pascual-Leone, J., \& Baillargeon, R. H. (1994). Developmental measurement of mental attention. International Journal of Behavioral Development, 17, 161-200. 
Pascual-Leone, J., Baillargeon, R., Lee, C., \& Ho, G. W. (1991). Towards standardization of mental capacity testing. Research Rep. No. 199. York University, Department of Psychology, Toronto.

Pascual-Leone, J., \& Goodman, D. (1979). Intelligence and experience: A neo-Piagetian approach. Instructional Science, 8, 301-367.

Pascual-Leone, J., \& Ijaz, H. (1989). Mental capacity testing as a form of intellectual-developmental assessment. In R. J. Samuda, S. L. Kong, J. Pascual-Leone, J. Cummins, \& J. Lewis (Eds.), Assessment and placement of minority students. A review for educators (pp. 143-171). Toronto, Canada: Hogrefe.

Pascual-Leone, J., \& Johnson, J. (1991). The psychological unit and its role in task analysis. A reinterpretation of object permanence. In M. Chandler \& M. Chapman (Eds.), Criteria for competence: Controversies in the assessment of children's abilities (pp. 153-187). Hillsdale, NJ: Erlbaum.

Pascual-Leone, J., \& Morra, S. (1991). Horizontality of water level: A neo-Piagetian developmental review. Advances in Child Development and Behavior, 23, 231-276.

Pascual-Leone, J. \& Smith, J. (1969). The encoding and decoding of symbols by children: A new experimental paradigm and a neo-Piagetian model. Journal of Experimental Child Psychology, 8, 328-355.

Pennings, A. (1988). The development of strategies in embedded figures tasks. International Journal of Psychology, 23, 65-78.

Shiffrin, R. M. (1988). Attention. In R. C. Atkinson, R. J. Herrnstein, G. Lindzey, \& R. D. Luce (Eds.), Stevens' handbook of experimental psychology (2nd ed., Vol. 2, pp. 863-952). New York: Wiley.

Witkin, H. A., Dyk, R. B., Faterson, H. F., Goodenough, D. R., \& Karp, S. A. (1962). Psychological differentiation. New York: Wiley.

Witkin, H. A., \& Goodenough, D. R. (1981). Cognitive styles: Essence and origins-Field dependence and field independence. New York: International Universities Press.

Witkin, H. A., Lewis, H. B., Hertzman, M., Machover, K., Meissner, P. B., \& Wapner, S. (1954). Personality through perception: An experimental and clinical study. New York: Harper \& Brothers.

Zelniker, T. (1989). Cognitive style and dimensions of information processing. In T. Globerson and T. Zelniker (Eds.), Cognitive style and cognitive development (pp. 172-191). Norwood, NJ: Ablex.

Received: April 28, 1996; revised: June 24, 1998 